\title{
LEARNING THE PROCEDURE ON TAKT PRODUCTION OF TPS BY METHODS ENGINEERING AND SIMULATION
}

\author{
Takakuwa, S.; Yang, W.* \& Nagatsuka, H. \\ Department of Industrial and Systems Engineering, Chuo University, \\ 1-13-27 Kasuga, Bunkyo-ku, Tokyo, 112-8551, Japan \\ E-Mail: takakuwa@indsys.chuo-u.ac.jp, yangwh@indsys.chuo-u.ac.jp, hideki@indsys.chuo-u.ac.jp \\ ( Corresponding author)
}

\begin{abstract}
A systematic procedure of experiments, performing simulation in conjunction with work measurement techniques, is introduced and aimed at undergraduate students in Industrial Engineering (IE) to learn a basic procedure for designing and implementing takt production in terms of the Toyota Production Systems (TPS). Students are split into small groups in a class. A series of experiments is designed and performed for an assembly line of magnetic contactors. Using the concept of the TPS, students perform work measurement studies including time study, process design, such as line balancing, and execute simulation experiments. At the end of the course, the teaching staff evaluates each group based on the performance of the simulation results.

(Received in May 2018, accepted in August 2018. This paper was with the authors 1 month for 1 revision.)
\end{abstract}

Key Words: Simulation Education, Takt Production, Toyota Production System (TPS), Work Measurement Technique

\section{INTRODUCTION}

In a undergraduate class of industrial engineering, courses focused on methods engineering and production management/operations management are commonly provided as one of the most basic and important subjects as well as an entry-level simulation. After studying methods engineering and production management/operations management, it would benefit junior or senior students to apply simulation experiments to real production activities. For that reason, a series of experiments that includes methods engineering together with simulation is introduced specifically to teach the basic procedure of takt production in terms of the Toyota Production System (TPS).

In general, courses at the undergraduate or graduate level that are focused on simulation provide an introduction to simulation using simulation languages or software such as Arena and Simio. It is standard for undergraduate or beginning graduate students to learn simulation in a formal course. The main objective of such a course is for students to build a simulation model based on exercises at the end of each chapter in the textbook as an assignment to enhance modelling skills.

On the other hand, students learn both traditional and recent industrial engineering techniques and methodologies, especially methods engineering and production management/operations management. Methods engineering or work measurement is a traditional and primary technique in industrial engineering. Work measurement comprises motion and time study, predetermined motion time systems, standard time, and work sampling. Time study consists of recording times and rates of work for elements of a specified job carried out under specified conditions to obtain the time necessary to carry out a job at a defined level of performance.

The TPS is one of the major components of classes directed at production management or operations management. In order to execute simulation experiments, a systematic procedure for module-based modelling is designed and proposed to simulate a multistage manufacturing 
flow-type system adopting a dual-card Kanban system with a delivery cycle [1, 2]. Functional analysis is performed to present Kanban flows in exactly the same fashion in a simulation model as they actually appear in a real manufacturing system. One shipping area module, one module of the required number of parts to be stored, and one supplier centre module are used to develop a designated simulation. In addition, a number of containers for assembly lines are optimized in the fixed-course pick-up system [3].

Customer demand must be considered first in the TPS. Simulation is effective to examine whether daily customer demand could be satisfied because class hours is usually limited, say, three hours at the class. In this paper, a series of procedures is introduced for undergraduate students in industrial engineering to learn a basic procedure for designing and implementing takt production of the TPS by performing simulation in conjunction with work measurement techniques.

\section{OUTLINE OF IE EXPERIMENTS}

\subsection{Takt production in terms of TPS}

The TPS is a framework of concepts and methods used to enhance corporate vitality. It is a production system providing the best quality, lowest cost, and shortest lead-time through the elimination of waste. Ohno (1988) categorized seven major wastes typically found at any workplace, i.e., wastes from overproduction, waiting, conveyance, over-processing, inventory, motion, and correction [4]. Overproduction is the worst form of waste; overproduction means producing more, sooner or faster than is required by the next process or customers.

Just-in-time is one of the major pillars of the TPS. An outline of just-in-time production is shown in Fig. 1. Just-in-time means that a system of production makes and delivers what is needed, just when it is needed, and just in the amount needed. Just-in-time is comprised of three elements: takt time, continuous flow, and pull system [5].

Takt time is how often a company should produce one part or product to meet customer requirements based on the rate of sales. Continuous flow means producing and moving one item at a time to match the takt time, with each item passed immediately from one process step to the next without stagnation in between. A core concept of the TPS is arranging all the processes in the production sequence in a single, smooth flow based on the rate of sales [6]. Hence, takt production is to be designed, taking takt time and continuous flow depicted in Fig. 1 into consideration.

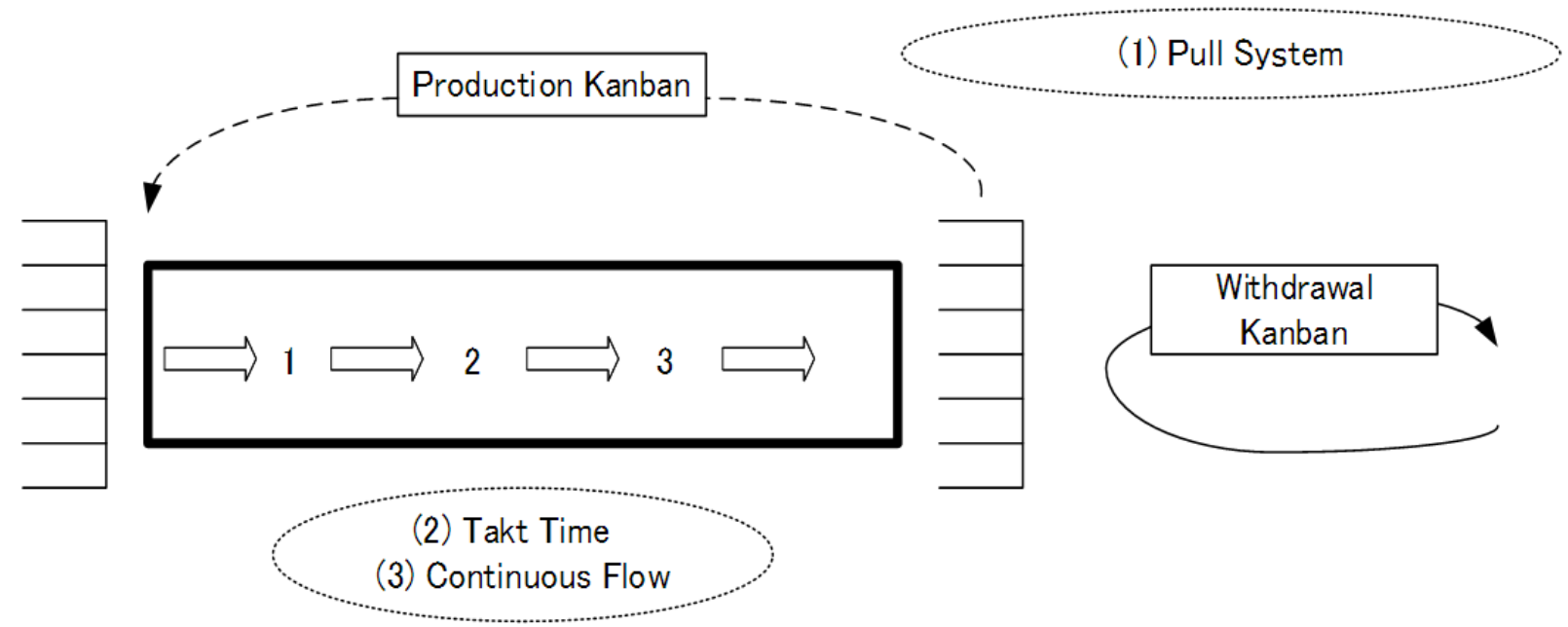

Figure 1: Outline of just-in-time production. 


\subsection{Product description}

Products to be assembled in the experiments are magnetic contactors [7]. Magnetic contactor is a form of electrical relay found on most electrically powered motors. When electricity flows through the magnetic contactor, it causes the electromagnet to generate a strong magnetic field. This field pulls the iron core into the coil, and creates an electrical arc. Electricity is passed through one contact and into the contactor's parent device in this manner. Parts of the magnetic contactor are summarized in Table I.

Table I: Parts of the magnetic contactor.

\begin{tabular}{|c|l|c|c|}
\hline Part No. & \multicolumn{1}{|c|}{ Part Name } & $\begin{array}{c}\text { Quantity } \\
\text { (pcs./unit) }\end{array}$ & $\begin{array}{c}\text { Unit cost } \\
(\$ \mathbf{p c} .)\end{array}$ \\
\hline 1 & fixed contact (A) & 8 & 0.3 \\
\hline 2 & fixed contact (B) & 2 & 0.3 \\
\hline 3 & flat fillister head screw (with spring washer) & 12 & 0.08 \\
\hline 4 & movable contact & 5 & 0.05 \\
\hline 5 & movable contact support & 1 & 5 \\
\hline 6 & backspring & 2 & 1.3 \\
\hline 7 & cushion spring & 2 & 0.1 \\
\hline 8 & magnet coil & 1 & 3.7 \\
\hline 9 & core (lower part) & 1 & 2.5 \\
\hline 10 & frame & 1 & 6 \\
\hline 11 & back cover (with electrical insulating paper) & 1 & 1.6 \\
\hline 12 & support & 1 & 0.35 \\
\hline 13 & AC terminal (A) & 1 & 0.5 \\
\hline 14 & AC terminal (B) & 1 & 0.5 \\
\hline 15 & small flat screw (with washer and spring lock washer) & 2 & 0.06 \\
\hline
\end{tabular}

\subsection{Assigned instruction and conditions}

Students learn the TPS, by performing experiments of simulation in conjunction with traditional work measurement techniques. An actual example used in the class of the industrial engineering experiments was an assembly operations of magnetic (or electromagnetic) contactors assigned to meet the daily production amount. The assignment in the textbook is described as follows:

(1) Daily production amount: 450 pieces/day.

(2) Product to be assembled: magnetic or electromagnetic contactors.

(3) Daily operation hours: 7 hours. Actual working hours is 8 hours and recess is 1 hour. An eight-hour workday.

(4) Conveyor speed: $0.2-3 \mathrm{~m} / \mathrm{min}$ step-less speed change.

(5) Cost of the belt conveyor: 10,000 \$/unit.

(6) Labour cost including overhead: 30 \$hour.

\subsection{Role-sharing in groups}

Students taking a course are divided into groups, with each group comprising approximately 20-25 people. Each student takes charge of one of the following tasks:

(1) Assembly operations: 5-7 people corresponding to the number of workstations.

(2) Providing the associated parts for assembly operators: 5-7 people.

(3) Time study using stopwatch method: 5-7 people.

(4) Energization test: 2 people.

(5) Motion study: 2-3 people. 


\section{PROCEDURE OF IE EXPERIMENT}

Prerequisites for the experiment course are methods engineering, production management or operations management including the TPS, and an entry-level simulation course in industrial engineering (IE). Students in the class are divided into a suitable number of groups.

\subsection{Basic flow of IE experiment}

A basic flow of the experiment is shown in Fig. 2, and summarized as follows:

(1) Work measurement

A series of traditional industrial engineering techniques such as time study and performance rating is used to obtain the standard time of work element for assembling a magnetic contactor.

(2) Process design

Process design is performed in terms of the TPS.

(3) Simulation experiments

Simulation analysis is performed to determine if the resulting process design can satisfy the production requirement.

(4) Evaluation of simulation results

Performance of each group is evaluated by the specified evaluation criteria.



Figure 2: Basic flow diagram of the experiment. 


\subsection{Work measurement}

One of the most critical requirements for time study is how to define work elements [8]. Work elements should be easily identifiable, with a definite beginning and ending so that they can be repeatedly recognized. They should be as short as can be conveniently timed by the observer. They should be chosen so that they represent naturally unified and distinct segments of the operation. Possible work elements for assembling magnetic contactors are listed in Table II. In Table II, standard time is obtained by time study, and D.M. stands for decimal minutes.

Table II: Possible work elements for assembling magnetic contactors.

\begin{tabular}{|c|c|c|c|}
\hline No. & Work Element & Preceding Work & $\begin{array}{c}\text { Standard } \\
\text { Time (D.M.) } \\
\end{array}$ \\
\hline 1 & Fit a fixed contact (A) into No. 1 marked on the frame. & none & 5.7 \\
\hline 2 & Fit a fixed contact (A) into No. 3 marked on the frame. & none & 5.7 \\
\hline 3 & Fit a fixed contact (A) into No. 5 marked on the frame. & none & 5.7 \\
\hline 4 & Fitg a fixed contact (A) into No. 13 marked on the frame. & none & 5.7 \\
\hline 5 & Fit a fixed contact (A) into No. 2 marked on the frame. & none & 5.7 \\
\hline 6 & Fit a fixed contact (A) into No. 4 marked on the frame. & none & 5.7 \\
\hline 7 & Fit a fixed contact (A) into No. 6 marked on the frame. & none & 5.7 \\
\hline 8 & Fit a fixed contact (A) into No. 14 marked on the frame. & none & 5.7 \\
\hline 9 & Tighten flat fillister head screw at No. 1 marked on the frame with a draver. & 1 & 17.4 \\
\hline 10 & Tighten flat fillister head screw at No. 3 marked on the frame with a draver. & 2 & 17.4 \\
\hline 11 & Tighten flat fillister head screw at No. 5 marked on the frame with a draver. & 3 & 17.4 \\
\hline 12 & Tighten flat fillister head screw at No. 13 marked on the frame with a draver. & 4 & 17.4 \\
\hline 13 & Tighten flat fillister head screw at No. 2 marked on the frame with a draver. & 5 & 17.4 \\
\hline 14 & Tighten flat fillister head screw at No. 4 marked on the frame with a draver. & 6 & 17.4 \\
\hline 15 & Tighten flat fillister head screw at No. 6 marked on the frame with a draver. & 7 & 17.4 \\
\hline 16 & Tighten flat fillister head screw at No. 14 marked on the frame with a draver. & 8 & 17.4 \\
\hline 17 & Fit fixed contact (B) to No. 10 marked on the frame, and tighten flat fillister head screw. & none & 27.1 \\
\hline 18 & Fit fixed contact (A) to No. 9 marked on the frame, and tighten flat fillister head screw. & none & 28.1 \\
\hline 19 & Fit core (upper part) inside the frame by hand. & none & 4.0 \\
\hline 20 & Insert magnet coil inside the frame, and connect code to fixed contact (A) and (B). & $17,18,19$ & 13.7 \\
\hline 21 & Fit backspring on inside core (upper part) by hand. & 19 & 8.3 \\
\hline 22 & Fit cushion springs on two hollows of magnet coil. & 20 & 7.9 \\
\hline 23 & Fit support on cushion spring by hand. & 22 & 4.4 \\
\hline 24 & Fit core (lower part) on support. & 23 & 4.1 \\
\hline 25 & Tighten two flat fillister head screws with a small driver, holding down back cover. & 21,24 & 61.1 \\
\hline 26 & Put movable contact on springat No. 1 with tweezers. & 19 & 9.6 \\
\hline 27 & Put movable contact on springat No. 3 with tweezers. & 19 & 9.6 \\
\hline 28 & Put movable contact on springat No. 5 with tweezers. & 19 & 9.6 \\
\hline 29 & Put movable contact on springat No. 13 with tweezers. & 19 & 9.6 \\
\hline 30 & Put movable contact on springat No. 15 with tweezers. & 19 & 9.9 \\
\hline 31 & Put fixed contact (B) at No. 15, tighten with adriver. & 30 & 7.8 \\
\hline 32 & Put fixed contact (B) at No. 16, tighten with adriver. & 30 & 7.8 \\
\hline 33 & Tighten flat fillister head screw at No. 15 marked on the frame with a draver. & 31 & 17.4 \\
\hline 34 & Tighten flat fillister head screw at No. 16 marked on the frame with a draver. & 32 & 17.4 \\
\hline
\end{tabular}

Time study is based on a record of observed times necessary for doing a job together with an assessment by the observer of the speed and effectiveness of the worker in relation to the observer's concept of standard rating. The performance rating adjusts the average observed time to what a trained worker could expect to accomplish working at a normal pace.

Standard time is the total time in which a job should be completed at standard performance. It comprises of work content, contingency allowance for delay, unoccupied time and interference allowance, where applicable. Standard time, ST (D.M. or sec), is determined using the Eq. (1): 


$$
S T=O T \times \frac{R F}{100} \times(1+A F)
$$

where:

$A F$ - allowance factor,

$O T$ - observed time (D.M. or sec),

$R F$ - rating factor.

\subsection{Procedure of process design in terms of the TPS}

A major process design is described to produce product items just in the amount needed, as shown in Fig. 2 [9].

Takt time means work time between two consecutive units. Takt production realizes continuous flow. Continuous flow means producing and moving one item at a time through a series of processing steps as continuously as possible, to match takt time, with each step making a product just as is required by the next step.

If a product item is produced one unit at a time at a constant rate during the net available work time, the takt time is the amount of time that must elapse between two consecutive unit completions to meet the demand.

Takt time, TT (sec/pc) is determined by available working time divided by customer demand rate [6].

$$
T T=\frac{T W}{U R}
$$

where:

$T W$ - available working time (sec/day)

$U R$ - customer demand rate (pieces/day).

The required minimum number of workers, $W R$ (persons or number of workstations), is determined by the total sum of work elements divided by the takt time obtained in Eq. (2) [6].

$$
W R=\frac{T O}{T T}
$$

where:

$T O$ - total sum of work elements ( $\mathrm{sec} / \mathrm{pc})$.

A flow-type assembly line is designed based on the flow of operations and the number of workers or workstations obtained in Eq. (3).

Line balancing is mostly concerned with assembly lines such as conveyor lines, and aims to optimize decision making by grouping work elements and assigning them to the same workstation such that their precedence order is assumed. Line balancing is a basic problem for a case of continuous mass production, where a single product item is assembled on a single assembly line [10]. In order to determine a proper line balance, basic information including work elements, their times and their sequence for completing each product item, structure of the assembly line (number of workstations) and their technological abilities are required. In other words, the purpose of line balancing is to assign work elements to each assigned workstation in a manner that every workstation has approximately the same amount of work to be done. Some modified genetic algorithms have been proposed to solve the balancing problems [11-13].

It is necessary that the number of workstations is never less than the number of work elements. The grouping is achieved by constructing a chain of collection of work elements assignable to workstations step by step. There are several heuristic approaches to obtain solutions of the line balancing problem. It is recommended to apply the method outlined by 
Kilbridge and Wester [14]. One possible result of the line balancing is shown in Fig. 3; six workstations are assigned the associated work elements.

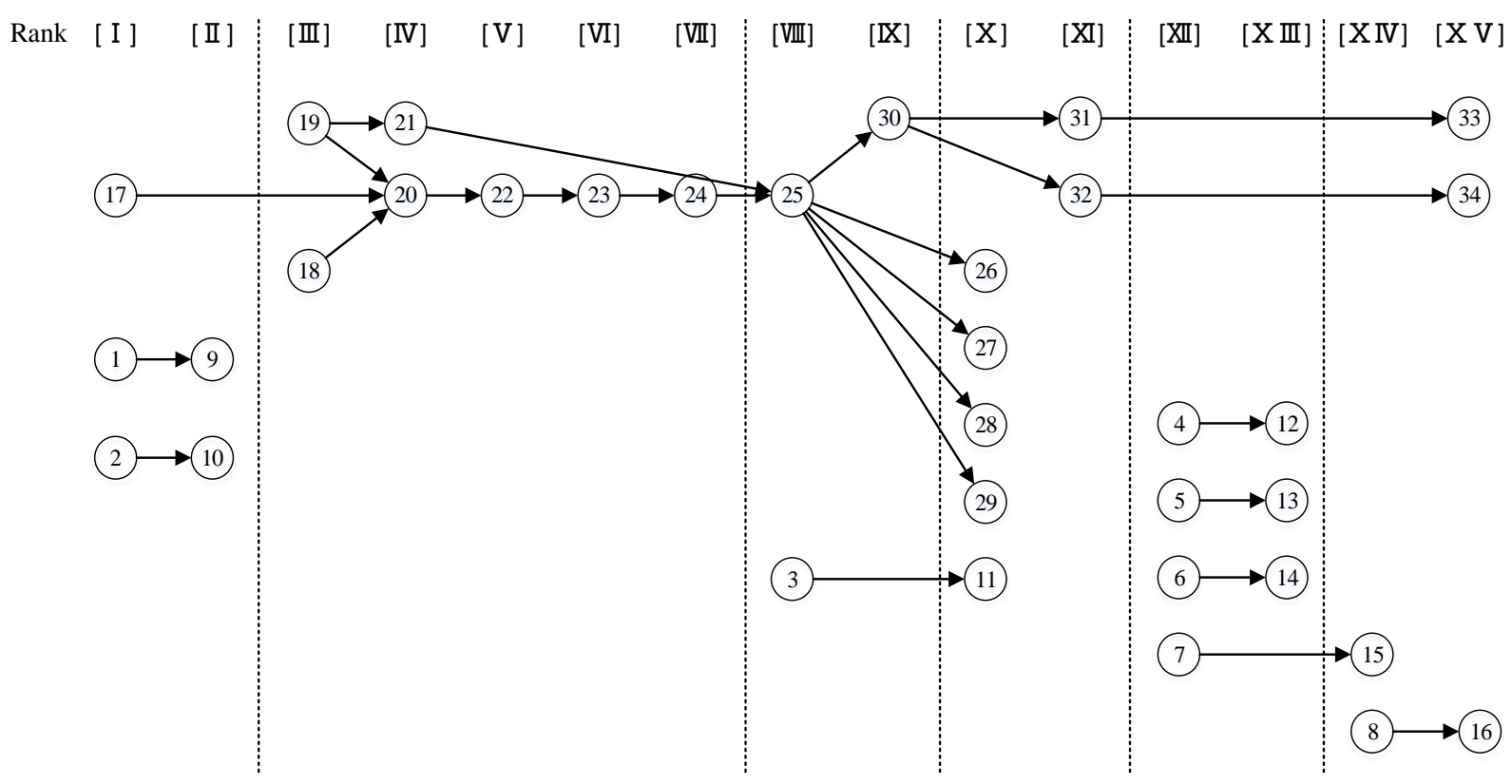

Figure 3: Possible result of the line balancing.

\section{SIMULATION EXPERIMENTS AND EVALUATION}

Because the class is time limited and is not long enough to perform assembly operations for a day, it is necessary to check whether performing simulation experiments could produce the given amount of finished products. Simulation models for an assembly line are constructed with Arena [15] and Simio [16]. In the following section, inputting data or parameters using Simio is illustrated.

\subsection{Executing simulation experiments}

Line production is dedicated to the needs of a single product. This is a repetitive production process in which each product passes through the same sequence of operations. Takt production is a special type of line production. Modelling of a line production system is relatively easy for students who have entry-level simulation modelling experience because line production can be modelled as a serial processing system.

The following components are illustrated:

(1) Processing time of operation at each workstation (see Fig. 4).

(2) Takt time.

(3) Proportion passing the energization test.

A completed Simio simulation model of a designated assembly line is shown in Fig. 5. In Fig. 5, simulation models of both the takt production system and the line production system are executed simultaneously in order to compare system performances.

Results are obtained after executing simulations on the following components:

(1) Confirming whether the required amount of finished products can be produced or not.

(2) Total production (completion) time if the required amount of finished products is satisfied.

(3) Number of non-conforming items. 


\subsection{Evaluating performance obtained by simulation experiments}

The performance of each group is evaluated by the specified evaluation criteria. Priorities of evaluation criteria are set as follows:

(1) Satisfy the amount of customer demand.

(2) Minimize the number of operators or workstations.

(3) Minimize the rate and proportion of non-conforming items.

(4) Minimize the total production time.

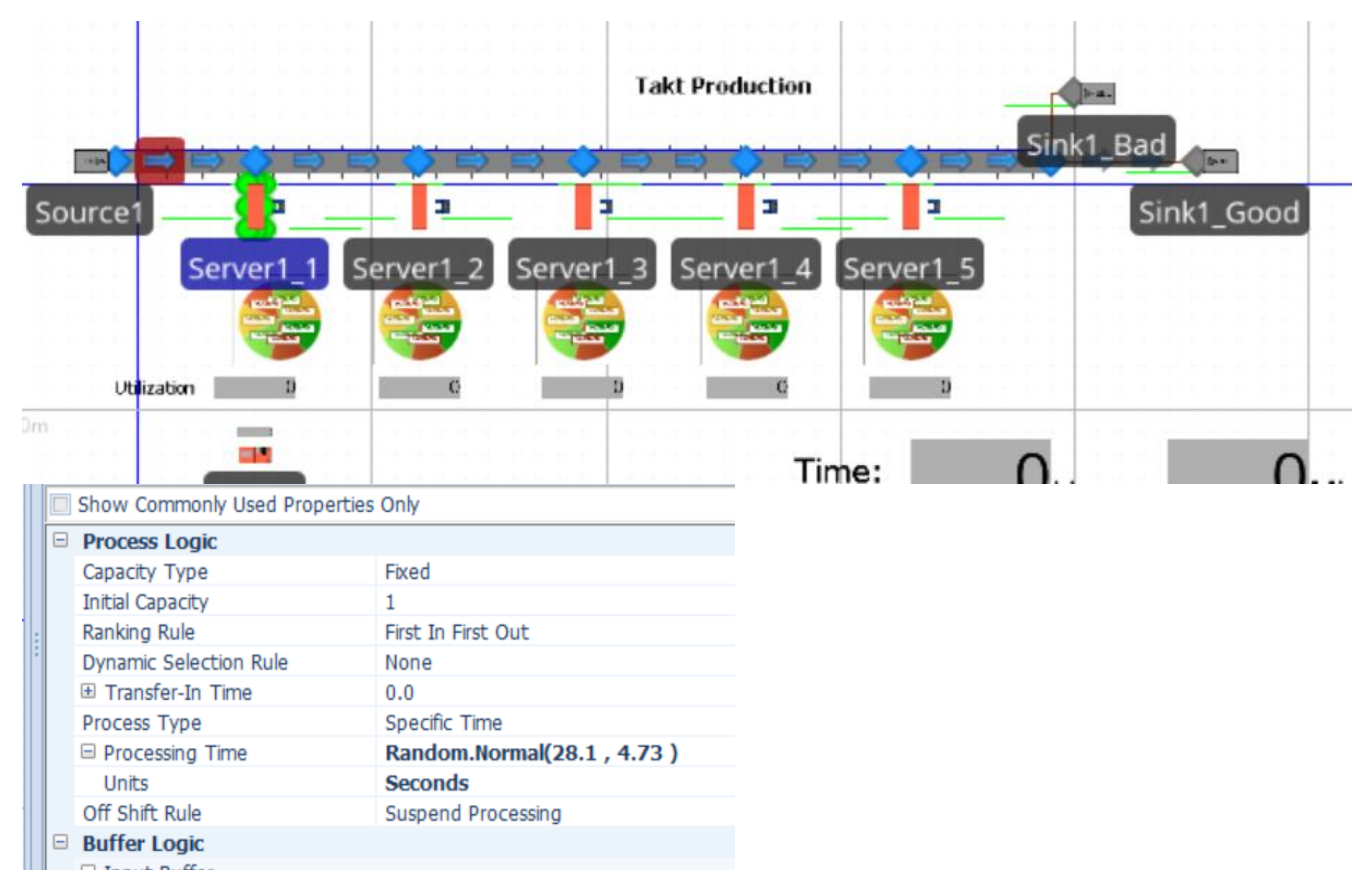

Figure 4: Inputting processing time of operation.

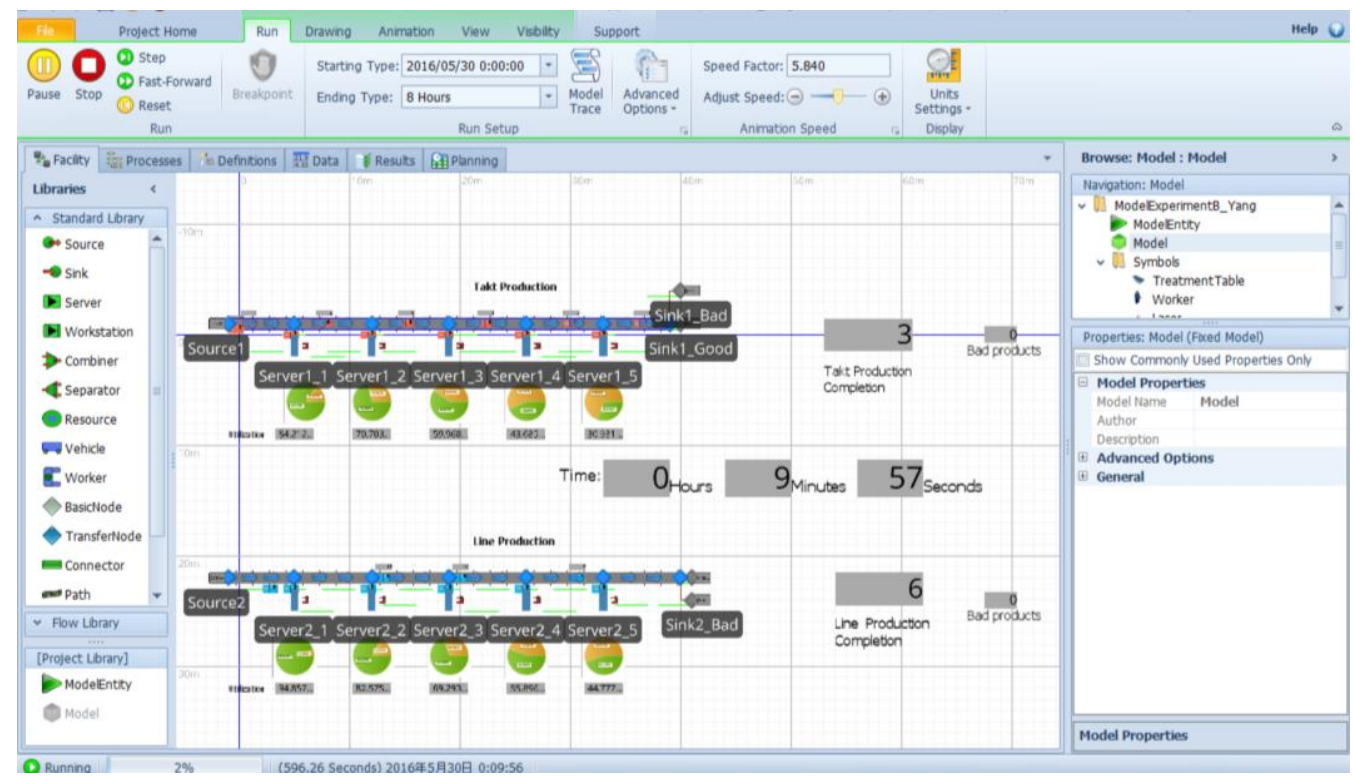

Figure 5: Executing simulation models.

If scores are tied on a top or higher priority or priorities among multiple groups, scores are to be checked further on a lower priority. Customer demand must be satisfied; this criterion is the absolute condition. Then, from the standpoint of operational costs, it is better to perform the entire works at the lowest cost. Waste stemming from corrections or defects is one of 
seven wastes that are categorized and typically found in any workplace. It is emphasized that defective parts or product items are never sent to the next process. Hence, when an operator makes defective products, he must stop them before they go to the next process; it will take necessary additional time to do the work again. Finally, operators may do other work during their free time after completing their assigned work. Sample results for evaluation are summarized together with the associated takt time in Table III and Fig. 6. In this case, the course instructor decides ranking as Groups C, A, D, and B in order, based on the abovementioned priorities of evaluation criteria.

Table III: Sample result on criteria of each group.

\begin{tabular}{|l|c|c|c|c|}
\hline \multicolumn{1}{|c|}{ Criteria } & Group A & Group B & Group C & Group D \\
\hline Number of workstations & 5 & 7 & 5 & 6 \\
\hline Rate of non-conforming items [\%] & 4 & 28 & 2 & 0 \\
\hline Takt time [sec] & 33.9 & 43.1 & 49.3 & 44 \\
\hline
\end{tabular}

Students learn the basic concept of the TPS and the related issues in class of production management/operations management. On the other hand, students can understand a basic procedure for designing and implementing takt production of TPS through the experiment course in a practical manner.

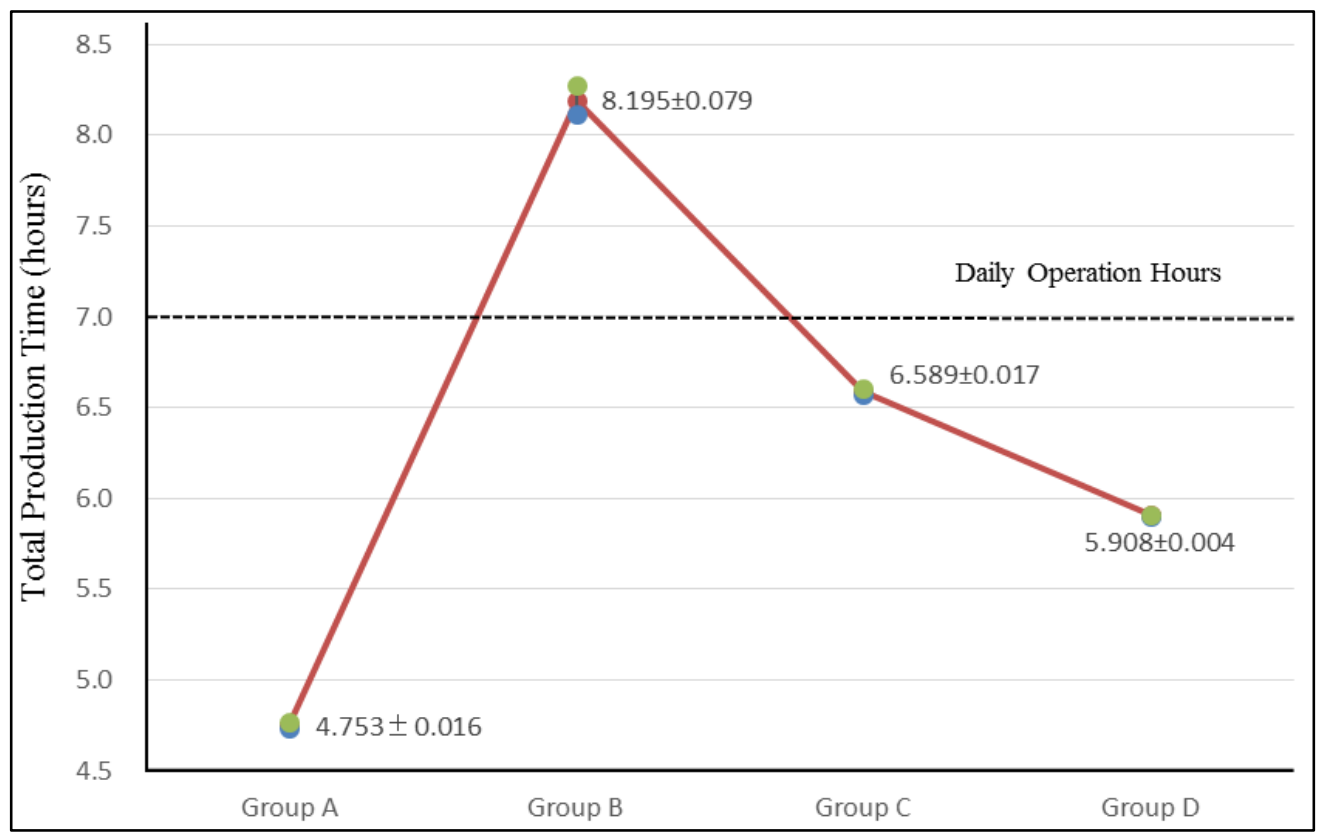

Figure 6: Sample results on total production time on each group.

\section{CONCLUSION}

A series of procedures is introduced for undergraduate students in industrial engineering to learn a basic procedure for planning and implementing takt time in terms of the TPS by performing simulations in conjunction with work measurement techniques. Students are split into small groups in each class. A series of experiments is performed based on the assembly line of magnetic contactors. First, students perform work measurement including time study, and process design such as line balancing. Then, students perform simulation experiments based on the results from the process planning and by considering the basic procedure of the TPS. Finally, the teaching staff evaluates each group based on the simulation results. It was found that both junior and senior students could understand how to apply simulation to real 
production activities through a series of experiments. It could be more effective to coordinate all associated classes on the TPS including methods engineering, production management/operations management, system simulation as well as an experiment class.

\section{ACKNOWLEDGEMENT}

This research was supported by the Department of Industrial and Systems Engineering, Chuo University. The authors wish to express their sincere gratitude to Mr. Utsugi, Mr. Kishimoto, and Mr. Fujiwara, teaching staff of the Department of Industrial and Systems Engineering, Chuo University for their kind suggestions and help.

\section{REFERENCES}

[1] Nomura, J.; Takakuwa, S. (2004). Module-based modeling of flow-type multistage manufacturing systems adopting dual-card kanban system, Proceedings of the 2004 Winter Simulation Conference, Vol. 2, 1065-1072, doi:10.1109/WSC.2004.1371430

[2] Miwa, K.; Nomura, J.; Takakuwa, S. (2016). Module-based modeling and analysis of a manufacturing system adopting a dual-card kanban system with a delivery cycle, Proceedings of the 2016 Winter Simulation Conference, 2832-2843, doi:10.1109/WSC.2016.7822319

[3] Nomura, J.; Takakuwa, S. (2006). Optimization of a number of containers for assembly lines: the fixed-course pick-up system, International Journal of Simulation Modelling, Vol. 5, No. 4, 155166, doi:10.2507/IJSIMM05(4)3.066

[4] Ohno, T. (1988). Toyota Production System: Beyond Large-Scale Production, Productivity Press, Tokyo (in Japanese)

[5] Narusawa, T.; Shook, J. (2008). Kaizen Express, $2^{\text {nd }}$ ed., Nikkan Kogyo Shimbun, Ltd., Tokyo

[6] Monden, Y. (1983). Toyota Production System: Practical Approach to Production Management, Industrial Engineering and Management Press, Institute of Industrial Engineers, Norcross

[7] Fuji Electric FA Components \& Systems Co., Ltd. Magnetic contactors-Magnetic starters, from http://www.fujielectric.com/fcs/index.html, accessed on 01-04-2018

[8] Niebel, B. W. (1982). Motion and Time Study, $10^{\text {th }}$ ed., R. D. Irwin, Homewood

[9] Takakuwa, S. (2015). Operations Management, Chuo-Keizai Sha., Tokyo (in Japanese)

[10] Hitomi, K. (1996). Manufacturing Systems Engineering, $2^{\text {nd }}$ ed., Taylor \& Francis, London

[11] Wang, Y.; Yang, O. (2017). Research on industrial assembly line balancing optimization based on genetic algorithm and Witness simulation, International Journal of Simulation Modelling, Vol. 16, No. 2, 334-342, doi:10.2507/IJSIMM16(2)CO8

[12] Yang, B.; Chen, W.; Lin, C. (2017). The algorithm and simulation of multi-objective sequence and balancing problem for mixed mode assembly line, International Journal of Simulation Modelling, Vol. 16, No. 2, 357-367, doi:10.2507/IJSIMM16(2)CO10

[13] He, S. H.; Li, X. D.; Wang, Y.; Zhu, H. H. (2017). An optimization model for automobile mixed assembly line under multiple constrains, International Journal of Simulation Modelling, Vol. 16, No. 4, 720-730, doi:10.2507/IJSIMM16(4)CO18

[14] Kilbridge, M. D.; Wester, L. (1962). A review of analytical systems of line balancing, Operations Research, Vol. 10, No. 5, 626-638, doi:10.1287/opre.10.5.626

[15] Kelton, W. D.; Sadowski, R. P.; Zupick, N. B. (2014). Simulation with Arena, $6^{\text {th }}$ ed., McGrawHill, Inc., New York

[16] Kelton, W. D.; Smith, J. S.; Sturrock, D. T. (2014). Simio and Simulation: Modeling, Analysis, Application, $3^{\text {rd }}$ ed., Simio LLC., Sewickley 